\title{
A Case for the Worldwide Collection of Primary Benign Brain Tumors
}

\author{
Bridget J. McCarthy ${ }^{a, b}$ Kate A. Schellinger ${ }^{a}$ Jennifer M. Propp ${ }^{a, b}$ \\ Carol Kruchko $^{\text {b }}$ Beatrice Malmer ${ }^{c}$ \\ ${ }^{a}$ Division of Epidemiology, School of Public Health, University of Illinois at Chicago, Chicago, Ill., and \\ ${ }^{b}$ Central Brain Tumor Registry of the United States, Hinsdale, III., USA; ${ }^{C}$ Department of Radiation Sciences, \\ Oncology, Umea University, Umea, Sweden
}

\section{Key Words}

Primary benign brain tumors $\cdot$ Epidemiology $\cdot$ Incidence

\begin{abstract}
Background: Incidence data on malignant tumors are reported by the International Agency for Research on Cancer, with 189,485 new malignant brain tumors globally in 2002. However, collection and reporting of benign brain tumors are not universal. The objective here is to encourage the collection of primary benign brain tumors worldwide. Methods: Worldwide numbers of primary benign brain tumors were estimated through published articles and cancer registry reports presenting directly or indirectly reported benign incidence rates or frequencies for regions or countries. Results: An estimated 186,678 benign brain tumors were diagnosed worldwide in 2002. The estimated numbers of benign brain tumors were higher in females than males $(105,918$ vs. 80,759$)$. Since many countries do not report primary benign brain tumors, the incidence rate estimates vary significantly by region. Conclusions: This is the first survey to assess worldwide numbers of benign brain tumors. Underreporting, non-standardized collection, lack of age-adjustment, and other causes of the varying incidence rates must be considered. However, the estimated number of benign
\end{abstract}

brain tumors approximately equals, and could exceed, the number of malignant brain tumors globally. Registration of primary benign brain histologies in different geographical areas and ethnicities could provide clues to the underlying causes of these tumors.

Copyright $\odot 2009$ S. Karger AG, Basel

\section{Introduction}

Historically, collection of tumor registry data has been limited to malignant tumors, as these tumors typically have worse health effects and outcomes and are most easily ascertained through the health care system. Brain tumors differ from other tumors in that both malignant and benign tumors can result in significant morbidity and mortality due to their intracranial location [1]. Therefore, collection of data on all primary brain tumors should be an important part of public health surveillance.

The Central Brain Tumor Registry of the United States (CBTRUS) began as a pilot study in 1991 with the objective of determining the feasibility of collecting data on all (malignant and non-malignant) primary brain tumors [2]. CBTRUS uses the term non-malignant to describe benign brain tumors in response to clinicians treating

\section{KARGER}

(C) 2009 S. Karger AG, Basel

Fax +41613061234 E-Mail karger@karger.ch www.karger.com www.karger.com/ned
Bridget J. McCarthy, PhD

Department of Epidemiology/Biostatistics, School of Public Health

University of Illinois at Chicago, 1603 W. Taylor St. (M/C 923)

Chicago, IL 60612 (USA)

Tel. +1 312996 0314, Fax +1 312413 2025, E-Mail bjm3@uic.edu 
patients and to cancer registrars coding primary brain tumors. However, this terminology is not universal, and the term benign will be used throughout this manuscript. The CBTRUS has reported incidence rates of all primary brain tumors for regions in the USA, with the addition of more registries over time, and has been active in promoting the collection of these data (www.cbtrus.org) [3]. With the passage of the Benign Brain Tumor Cancer Registries Amendment Act (Public Law 107-260), the collection of all primary brain tumors became mandated in the USA beginning with cases diagnosed in 2004 .

Worldwide data on malignant brain tumors are publicly available from the International Agency for Research on Cancer (IARC) through their publication Cancer Incidence in Five Continents and through their online database, Globocan 2002 (www-dep.iarc.fr) [4]. Using Globocan 2002, the worldwide incidence rate for malignant brain tumors was estimated at 3.7/100,000 person-years (p-y) in males and 2.6/100,000 p-y in females, with a higher incidence in developed countries (males = $5.8 / 100,000 \mathrm{p}$-y; females $=4.1 / 100,000 \mathrm{p}-\mathrm{y}$ ) than in less developed countries (males $=3.0 / 100,000 \mathrm{p}$-y; females $=$ 2.1/100,000 p-y). The estimated numbers of new malignant brain tumor cases diagnosed in 2002 comprised 108,221 males and 81,264 females.

Data on benign brain tumors are more limited. Benign histologies include meningiomas (the most frequent benign histology), nerve sheath tumors (including acoustic neuromas), and pituitary tumors, as well as many other histopathologies [3]. Some countries, such as Sweden and Denmark, have been recording benign brain tumors since the 1950s, but many other countries have not collected this information or have not collected it in a standardized manner. In collaboration with the International Brain Tumor Alliance, the CBTRUS has attempted to assess what information is publicly available on the incidence of benign brain tumors worldwide. The primary objective of this manuscript was to estimate the number of benign brain tumors worldwide by gender and region, with the broad aim of promoting the collection of data on all benign brain tumors in every nation.

\section{Methods}

An extensive literature and registry search was conducted to find published articles and reports from tumor registries that included data on all primary benign and malignant brain and CNS tumors [International Statistical Classification of Diseases and Related Health Problems, 10th revision (ICD-10), site codes: D32D33, D35.2-35.4, D42-D43, D44.3-D44.5 or International Clas- sification of Disease for Oncology, 3rd edition (ICD-O-3), site codes: C70.0-C72.9 and C75.1-C75.3] for all ages at diagnosis and irrespective of the years of data collection, but available prior to March 2007 [5, 6]. Publications that calculated incidence rates or frequencies specific to tumors for pediatric or adult age groups were not included. Articles or registries with exclusively malignant data were also excluded. The data of interest were benign tumor incidence rates, total brain and CNS tumor incidence rates (including tumors with benign behaviors), or frequencies of tumors with histology types known to exhibit benign behavior (such as meningioma, schwannoma/neurilemmoma/neurinoma, or craniopharyngioma) [3, 7-37]. Tumors of benign and uncertain behavior are usually identified by ICD-0-3 behavior codes of 1 (benign) or 1 (uncertain) or through the ICD-10 codes identified above. However, given the variability in the methodology and often the lack of specific descriptions regarding tumor behavior in published data, it was impossible to strictly define benign brain tumors for this study, and histologies that are primarily of nonmalignant behavior, e.g. meningioma and nerve sheath, were categorized as benign for the current study. Most low-grade gliomas (e.g. oligodendrogliomas, diffuse and fibrillary astrocytomas, etc.) are coded with a malignant behavior in ICD-O-3, and therefore would be excluded from these benign estimates.

A model based on Globocan was created to estimate the global numbers of benign brain and CNS tumors [4, 38]. The Globocan 2002 software was used to obtain population estimates and incidence rates of malignant tumors [4]. The world regions used in Globocan 2002, as defined by the United Nations Population Division, were also used to estimate the benign brain tumor incidence rates by gender and region. The developed world regions included countries from the following regions: Northern America, Japan, Eastern Europe, Northern Europe, Southern Europe, Western Europe, Australia/New Zealand, while the less developed world regions included countries from the following regions: Eastern Africa, Northern Africa, Southern Africa, Western Africa, Caribbean, Central America, South America, Eastern Asia (excluding Japan), South-Eastern Asia, South-Central Asia, Western Asia, Melanesia, Micronesia, and Polynesia (a full description of the countries in each region can be found at wwwdep.iarc.fr/globocan_frame.htm). Malignant tumor incidence rates for each country are available in Globocan 2002 (http://depiarc.fr) [4].

Five methods were devised to estimate the number of benign tumor cases using the 2002 population as estimated by Globocan 2002:

(1) A benign incidence rate for an entire country from a published peer-reviewed article or a tumor registry report was used directly to calculate estimated number of cases.

(2) Incidence rates for all primary (malignant and benign) brain tumors were obtained from a published article or a tumor registry report. The Globocan 2002 incidence rate for malignant tumors in that country was subtracted from the total published incidence rate to obtain the benign incidence rate. The number of cases was then calculated from that estimated incidence rate.

(3) Frequencies of benign tumor histology types from a published article or tumor registry report were summed; the remaining percentage was assumed to be malignant. The percentage of malignant tumors and total number of cases from Globocan were then used to estimate the total number of all primary tu- 


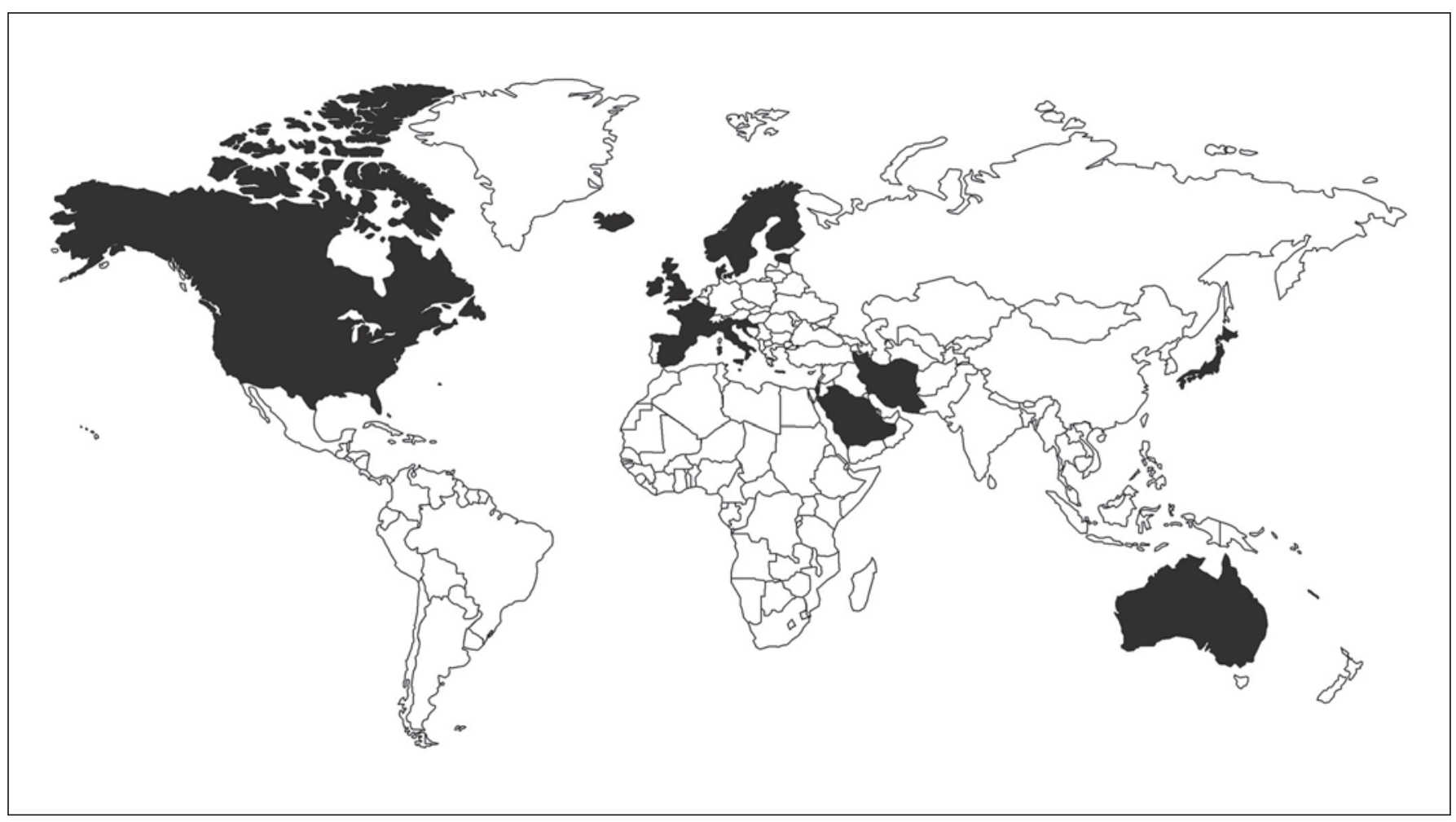

Fig. 1. Countries or regional registries within a country reporting an incidence rate for primary benign or all primary brain tumors (includes countries estimated using methods 1,2 or 5).

mors. The estimated number of benign tumors was calculated by subtraction of the number of malignant tumors from the estimated total of all tumors.

(4) Estimation of incidence rates for a country with no data was done by applying known benign incidence rate data from a neighboring or ethnically similar country to the population of the country with no data in order to obtain an estimated number of benign cases.

(5) Regional incidence data from a published article or tumor registry report were used to estimate cases for that entire country.

A listing of the method used for each country has been provided (online suppl. table 1; for all supplementary material see www.karger.com/doi/10.1159/000230808). Cases were totaled for each world region, and incidence rates were estimated for each world region per 100,000 p-y using the total regional population from Globocan 2002 [4]. In world regions where gender-specific data were not available, gender-specific rates from similar neighboring regions were applied. Incidence rates were calculated by region and by gender. Age-specific data were generally not available, so world regional incidence rates were not age-adjusted. The estimated numbers of brain tumors worldwide were calculated by summing the estimated numbers across regions.

\section{Results}

Published incidence data were available more frequently in developed regions than in less developed regions (fig. 1; table 1). Published incidence rates for benign or all primary brain tumors by country or by regional population-based registries within a country (methods 1 , 2 or 5) were only available for $12 \%$ of countries worldwide. The majority of countries, particularly the world regions of South and Central America, Eastern Europe, Africa, the Caribbean, Polynesia, Melanesia, and Micronesia, lacked published registry data for benign brain tumor incidence rate estimation.

The estimated number of new benign brain tumor cases worldwide for 2002 comprised 80,759 males and 105,918 females, for an estimated total of 186,678 new benign cases diagnosed in the world in 2002 (table 2). Estimated benign crude incidence rates were higher in more developed world regions (4.9/100,000 p-y for males and $7.3 / 100,000 \mathrm{p}-\mathrm{y}$ for females) than in less developed regions (1.9/100,000 p-y for males and 2.3/100,000 p-y for females), following a similar pattern in malignant crude 
Table 1. Proportion of countries per region according to method used for estimating incidence and number of benign brain tumors

\begin{tabular}{|c|c|c|c|c|c|c|}
\hline & \multirow{2}{*}{$\begin{array}{l}\text { Coun- } \\
\text { tries, n }\end{array}$} & \multicolumn{5}{|c|}{ Method, \% } \\
\hline & & 1 & 2 & 3 & 4 & 5 \\
\hline Eastern Europe & 10 & - & - & 10 & 90 & - \\
\hline Northern Europe & 10 & 20 & 50 & - & 20 & 10 \\
\hline Southern Europe & 11 & 9 & - & - & 64 & 27 \\
\hline Western Europe & 7 & - & 14 & - & 86 & - \\
\hline Eastern Africa & 16 & - & - & 6 & 94 & - \\
\hline Middle Africa & 8 & - & - & - & 100 & - \\
\hline Northern Africa & 6 & - & - & 33 & 66 & - \\
\hline Southern Africa & 5 & - & - & - & 100 & - \\
\hline Western Africa & 16 & - & - & 12 & 88 & - \\
\hline Caribbean & 8 & - & - & 12 & 88 & - \\
\hline Central America & 8 & - & - & 12 & 88 & - \\
\hline South America & 12 & - & - & - & 100 & - \\
\hline North America & 2 & - & - & - & - & 100 \\
\hline Eastern Asia & 5 & - & - & 40 & 40 & 20 \\
\hline South-Eastern Asia & 10 & - & - & 10 & 90 & - \\
\hline South-Central Asia & 13 & - & 8 & 8 & 84 & - \\
\hline Western Asia & 17 & - & 6 & - & 88 & 6 \\
\hline Polynesia & 1 & - & - & - & 100 & - \\
\hline Micronesia & 1 & - & - & - & 100 & - \\
\hline Melanesia & 5 & - & - & - & 100 & - \\
\hline \multicolumn{7}{|l|}{ Australia, New } \\
\hline Zealand & 2 & 50 & - & - & 50 & - \\
\hline World & 173 & 2 & 5 & 7 & 81 & 5 \\
\hline
\end{tabular}

incidence rates. The developed region with the highest estimated benign incidence rate was Western Europe, which was followed by North America. The lowest rates were found in Africa and the Caribbean. Estimated benign incidence rates between males and females were least different in less developed regions like Africa and the Caribbean (males $=0.5 / 100,000$ p-y; females = $0.6 / 100,000$ p-y).

\section{Discussion}

The broad aim of this review was to encourage the worldwide collection of all primary malignant and benign brain and CNS tumors. Because the majority of countries around the world do not currently collect benign brain tumor data, and because incidence rates for many of the countries that do collect benign brain tumors were often not publicly available by gender or age group, the incidence rates calculated are very crude. As a comparison to the global number of primary brain tumors estimated here, we applied age- and gender-specific benign incidence rates in the USA [3] to the world population for 2002 (source: www-dep.iarc.fr/GLOBOCAN frame.htm). The overall benign incidence rate was found to be 2.6 per 100,000 p-y for an expected number of approximately 160,000 benign brain tumors worldwide, with the number of tumors in males (over 60,000) lower than in females (almost 100,000). Although the estimated numbers based on US incidence rates are slightly lower than the estimated numbers calculated from the published data reported, it is likely that the published data better represent the number of brain tumors in the world in 2002.

Some limitations of the methodology used to calculate these estimates include the lack of data on all primary brain tumors for many countries, especially in South America, Africa, and Asia (fig. 1; table 1; online suppl. table 1). Other than obtaining a direct estimate of the incidence rate for a specific country (only $2 \%$ of all countries worldwide prior to March 2007), all of the other methods employed here, such as utilizing data from a neighboring country, using regional registries to represent the whole country, or using data on the frequencies of tumors seen and then attempting to convert these to incidence rates, are unlikely to accurately represent the true underlying incidence rate of primary benign brain tumors in those countries. In fact, the least accurate methods of estimation (methods 3 and 4) were used for $88 \%$ of countries in the world. For most countries where frequencies of tumors were estimated (method 3), the sample of cases were hospital-based rather than population-based, primarily because of the lack of any available data; whereas for countries or regions of countries reporting incidence rates, the published data were restricted to population-based estimates. Even comparing incidence rates between countries or regions of countries that do collect data on all primary brain tumors, the years of data collection are not consistent and adjustment methods, such as using different standard populations, may vary. The methodology used to estimate incidence rates in this study was loosely based on the methodology used by the IARC for their Globocan database, as defined on the website (www-dep.iarc.fr/) [4]. For malignant cancers, IARC uses 5 methods to estimate incidence rates, including use of national incidence data, regional incidence data, frequency data, data from neighboring countries, or mortality data, and a description of which method was used for each country is available on their website. As mortality data for benign brain tumors are generally 
Table 2. Benign brain/CNS tumor numbers and crude incidence rates estimated from published data [3, 7-37] and crude incidence rates for malignant brain tumors from Globocan 2002 [4] by region and gender

\begin{tabular}{|c|c|c|c|c|c|c|c|c|}
\hline & \multicolumn{3}{|c|}{$\begin{array}{l}\text { Estimated numbers of benign } \\
\text { brain tumors }\end{array}$} & \multicolumn{3}{|c|}{$\begin{array}{l}\text { Crude estimated benign } \\
\text { brain tumor incidence rates } \\
\text { per } 100,000 \text { person-years }{ }^{1}\end{array}$} & \multicolumn{2}{|c|}{$\begin{array}{l}\text { Crude malignant brain } \\
\text { tumor incidence rates } \\
\text { per } 100,000 \text { person-years }{ }^{1}\end{array}$} \\
\hline & male & female & overall & male & female & overall & male & female \\
\hline Eastern Europe & 4,179 & 7,719 & 11,898 & 3.0 & 4.9 & 4.0 & 5.8 & 4.5 \\
\hline Northern Europe & 1,569 & 2,335 & 3,904 & 3.4 & 4.8 & 4.1 & 8.6 & 6.5 \\
\hline Southern Europe & 2,129 & 3,684 & 5,813 & 3.0 & 4.9 & 4.0 & 9.3 & 7.4 \\
\hline Western Europe & 6,632 & 10,145 & 16,778 & 7.3 & 10.7 & 9.0 & 8.8 & 6.5 \\
\hline Eastern Africa & 641 & 896 & 1,537 & 0.5 & 0.6 & 0.5 & 1.2 & 1.2 \\
\hline Middle Africa & 241 & 337 & 578 & 0.5 & 0.6 & 0.5 & 0.2 & 0.2 \\
\hline Northern Africa & 439 & 596 & 1,035 & 0.5 & 0.6 & 0.5 & 1.7 & 1.1 \\
\hline Southern Africa & 116 & 168 & 284 & 0.5 & 0.6 & 0.5 & 1.3 & 1.0 \\
\hline Western Africa & 591 & 805 & 1,396 & 0.5 & 0.6 & 0.5 & 0.7 & 0.9 \\
\hline Caribbean & 90 & 124 & 214 & 0.5 & 0.6 & 0.5 & 3.3 & 2.5 \\
\hline Central America & 2,158 & 3,659 & 5,817 & 3.0 & 4.9 & 4.0 & 3.0 & 2.2 \\
\hline South America & 5,474 & 9,254 & 14,728 & 3.0 & 4.9 & 4.0 & 4.5 & 3.6 \\
\hline North America & 9,392 & 14,234 & 23,626 & 5.7 & 8.4 & 7.1 & 7.6 & 5.7 \\
\hline Eastern Asia & 18,482 & 19,647 & 38,129 & 2.4 & 2.6 & 2.5 & 3.9 & 2.9 \\
\hline South-Eastern Asia & 6,582 & 7,330 & 13,912 & 2.4 & 2.6 & 2.5 & 1.5 & 1.1 \\
\hline South-Central Asia & 19,592 & 20,591 & 40,183 & 2.4 & 2.6 & 2.5 & 2.1 & 1.4 \\
\hline Western Asia & 1,865 & 3,591 & 5,456 & 1.7 & 3.4 & 2.6 & 3.6 & 3.1 \\
\hline Polynesia & 8 & 8 & 16 & 2.4 & 2.6 & 2.5 & 1.6 & 4.0 \\
\hline Micronesia & 7 & 7 & 14 & 2.4 & 2.6 & 2.5 & 0.7 & 1.2 \\
\hline Melanesia & 94 & 99 & 194 & 2.4 & 2.6 & 2.5 & 1.4 & 0.4 \\
\hline Australia, New Zealand & 478 & 689 & 1,166 & 4.0 & 5.7 & 4.9 & 8.4 & 5.9 \\
\hline World & 80,759 & 105,918 & 186,678 & & & & & \\
\hline
\end{tabular}

${ }^{1}$ Estimated incidence rates are not age-standardized rates and are not directly comparable across regions due to differences in the age structure of the populations.

unavailable, we were unable to use this method to estimate or modify incidence rates for benign brain tumors. However, variations on the other 4 methods were applied to published data in an attempt to approximate a worldwide estimate of benign brain tumors. The use of different methodologies and data collection practices make assessment of even published incidence rates within and between regions difficult, leading to a very rough estimate of benign brain tumors worldwide.

Using data collected over a wide timeframe forces the assumption that brain tumor incidence rates have not changed for more than 40 years, an assumption which is not true, even if only taking into account improvements in diagnosis, reporting, and ascertainment [28, 39-44]. Age-specific incidence rates, or even tumor frequencies, were not available for most of the data assessed, which made refining the estimates to account for age impossible. As benign brain tumor histologies are more common in adults, future studies which separately assess incidence rates in children and adults would be beneficial in refining worldwide estimates. However, we were able to estimate incidence rates by gender which is important because of the significant differences in incidence rates by gender for malignant (higher incidence rates in males) compared to benign brain tumors (higher incidence rates in females, due primarily to meningiomas) [3].

Apart from the limitations in the methodology, other potential reasons for the large differences in the incidence rates of all primary brain tumors between regions or countries exist. Under-reporting or non-reporting of tumors, especially of benign tumors, is likely to be a problem, particularly in regions with limited access of individuals to diagnostic equipment and/or care and limited funding for ascertainment by cancer registries. In the Danish Cancer Registry between 1943 and 1997, a maximal annual incidence was observed for gliomas but not 
for meningiomas, suggesting that by the end of the study under-reporting due to improved diagnostic capability was perhaps still present for a primarily benign brain tumor [45]. Differences in reporting criteria between registries may also contribute to differences in incidence rates. For example, prior to passage of the Benign Brain Tumor Cancer Registries Amendment Act (Public Law 107-206) in the USA in 2002, collection of all primary brain tumors was state cancer registry specific. Collection of brain tumor data by CBTRUS prior to 2004, when the law went into effect, varied between registries, with one registry excluding spinal cord tumors, while another registry only ascertained histologically confirmed tumors [3]. Standardization of ascertainment and reporting criteria will be essential for accurate comparisons of incidence rates on a global scale $[1,46]$.

Accurate reporting of benign primary brain tumors worldwide would provide the opportunity to identify important patterns or associations in diverse factors, such as the age distribution between populations, mortality due to competing causes, differences in exposures to potential risk factors, and racial/ethnic differences. As the incidence rates of brain tumors increase with age, countries with an aging population, e.g. the USA, may have a higher incidence rate than countries with a younger age distribution. Age-adjustment could alleviate this bias, but was not possible to perform here. Similarly, countries where mortality from causes such as infectious disease result in death before cancer can develop will have lower incidence rates than countries where cancer is a more frequent cause of death. Strong risk factors could change incidence rates on a population level. Examples of this include the 'epidemic' of meningioma seen in Israel after large numbers of immigrants were exposed to ionizing radiation for treatment of tinea capitis, the increase in brain tumors in the Japanese atomic bomb survivors, and the increase in secondary tumors in those treated with irradiation for other cancers [47-54]. Differential distributions of other risk factors, such as frequencies of inherited conditions associated with brain tumors [55] or use of exogenous hormones [56, 57], may also influence incidence rates by region or gender. Within the USA, incidence rates of all primary brain tumors are lower in African-Americans than in Caucasians, while Hispanics have an incidence rate that is intermediate to these other two racial/ethnic groups [2]. It can be hypothesized that the race or ethnic composition of a country may influence the incidence rate of brain tumors, and may account for some of the differences in incidence rates between countries. Based on the current literature assessment, it is difficult to determine whether the very low incidence rates in the regions in Africa and other developing regions truly exists or whether it is an artifact of one or a combination of these issues.

\section{Conclusion}

This is the first survey to estimate the worldwide numbers of primary benign brain tumors. All primary brain and CNS tumors should be included in cancer registry collection and reporting since their exclusion causes an underestimation of the burden of this type of tumor. Currently benign brain tumors are included in some, but not all cancer registries. The systematic collection of both malignant and benign tumor types is important to assess their public health impact, and could reveal clues to the etiological factors in primary benign brain tumors which, to date, are largely unknown. The CBTRUS has collaborated with individuals in several countries (including France, India, and England) to promote nationwide registration of all primary brain tumors and continues to support the collection of all primary brain tumors worldwide.

\section{Acknowledgments and Funding}

This work was conducted under contract to The Central Brain Tumor Registry of the United States and was supported by a direct grant from the International Brain Tumor Alliance. CBTRUS data collection was supported by the American Brain Tumor Association, the National Brain Tumor Foundation, and the Pediatric Brain Tumor Foundation. B.M. was supported by the Acta Oncologica Foundation for the research fellow reward at the Royal Swedish Academy of Science.

References

1 Davis FG, Bruner JM, Surawicz TS: The rationale for standardized registration and reporting of brain and central nervous system tumors in population-based cancer registries. Neuroepidemiology 1997;16:308-316.

-2 Davis FG, Malinski N, Haenszel W, Chang J, Flannery J, Gershman S, Dibble R, Bigner DD: Primary brain tumor incidence rates in four United States regions, 1985-1989: a pilot study. Neuroepidemiology 1996;15:103112 .

3 CBTRUS: Statistical Report: Primary Brain Tumors in the United States, 1998-2002. Hinsdale, Central Brain Tumor Registry of the United States, 2005. 
4 Ferlay J, Bray F, Pisani P, Parkin DM: GLOBOCAN 2002: Cancer Incidence, Mortality and Prevalence Worldwide. IARC CancerBase No. 5, version 2.0. Lyon, IARC, 2004.

5 WHO: International Statistical Classification of Diseases and Related Health Problems, 10th Revision, ICD-10. Geneva, WHO, 1992.

6 Fritz A, Ries L: International Classification of Diseases for Oncology, ed 3. Bethesda, National Institutes of Health, 1998.

7 Abu-Salih HS, Abdul-Rahman AM: Tumors of the brain in the Sudan. Surg Neurol 1988; 29:194-196.

-8 Amarti A, Ottmani S, Maher M, Bernoussi Z, Khamlichi A, Saidi A: Central nervous system tumors in Morocco: retrospective analysis of 2,374 cases. J Neurosurg Sci 2001; 45:163-170.

-9 Andrews NB, Ramesh R, Odjidja T: A preliminary survey of central nervous system tumors in Tema, Ghana. West African J Med 2003;22:167-172.

10 Cancer Registry of Norway: Cancer in Norway 2005. www.kreftregisteret.no/en/General/Publications/Cancer-in-Norway (accessed February 12, 2007).

11 Danish Cancer Registry: Incidence of Cancer in Denmark 1998. Copenhagen, Danish National Board of Health, 2002.

12 Dobec-Meić B, Pikija S, Cvetko D, Trkulja V, Pazanin L, Kudelić N, Rotim K, Pavlicek I, Kostanjevec AR: Intracranial tumors in adult population of the Varazdin County (Croatia) 1996-2004: a population-based retrospective incidence study. J Neurooncol 2006;78:303-310.

-13 Elia-Pasquet S, Provost D, Jaffré A, Loiseau H, Vital A, Kantor G, Maire JP, Dautheribes M, Darrouzet V, Dartigues JF, Brochard P, Baldi I, Work Group: Incidence of central nervous system tumors in Gironde, France. Neuroepidemiol 2004;23:110-117.

14 Ferrari G, Lovaste MG, Moresco M, Rossi G: Primary intracranial tumors: survey of incidence in the province of Trento in the years 1977-1981. Italian J Neurol Sci 1985;6:191196.

15 Finnish Cancer Registry: Cancer in Finland 2002 and 2003 (Publication No. 66). Helsinki, Cancer Society of Finland, 2005.

16 Ibrahim AW: CNS tumors in eastern Saudi Arabia. Neurosurg Rev 1992;15:295-302.

17 Icelandic Cancer Registry, Heilaæxli og önnur æxli í miðtaugakerfi ICD10:C70-C72, 2002-2006. Reykjavik. Iceland. http://www. krabbameinsskra.is/index.jsp?icd=C70-C72 (accessed September 29, 2006).

18 Israel National Cancer Registry: 2002 Statistics. 2005. www.health.gov.il/pages/default. asp? maincat $=22 \&$ catid $=183 \&$ pageid $=1614$ (accessed September 29, 2006).

19 Kaye AH, Giles GG, Gonzales M: Primary central nervous system tumours in Australia: a profile of clinical practice from the Australian Brain Tumour Register. Aus NZ J Surg 1993;63:33-38.
20 Kuratsu J, Takeshima H, Ushio Y: Trends in the incidence of primary intracranial tumors in Kumamoto, Japan. Int J Clin Oncol 2001;6:183-191.

21 Lalitha VS, Dastur DK: Neoplasms of the central nervous system - histological types in 2,237 cases. Indian J Cancer 1980;17:102106.

22 Liigant A, Asser T, Kulla A, Kaasik AE: Epidemiology of primary central nervous system tumors in Estonia. Neuroepidemiol 2000;19:300-311.

23 Lopez-Gonzalez MA, Sotelo J: Brain tumors in Mexico: characteristics and prognosis of glioblastoma. Surg Neurol 2000;53:157-162.

24 Mwangombe NJ, Ombachi RB: Brain tumours at the Kenyatta National Hospital, Nairobi. East African Med J 2000;77:444447.

25 National Cancer Registry Ireland: Cancer in Ireland 1994-2001. Cork, Ireland, 2005. http://www.ncri.ie/ncri/index.shtml (accessed February 12, 2007).

26 Northern and Yorkshire Cancer Registry and Information Service: Registrations, Incidence Rates, Deaths \& Mortality Rates 2004. http://www.nycris.nhs.uk/uploads/ doc53_1_nycris2004.pdf (accessed September 29, 2006).

27 Ohaegbulam SC, Saddeqi N, Ikerionwu S: Intracranial tumors in Enugu, Nigeria. Cancer 1980;46:2322-2324.

28 Pirouzmand F, Sadanand V: The incidence trends of primary brain tumors in Saskatchewan from 1970 to 2001. Canadian J Neurol Sci 2007;34:181-186.

29 Razdlovsky EY: Tumors of the Brain. Moscow, Izdatelstvo Meditsina, 1954, pp 12-13, 206-207.

30 Raju GC, Adam R, Ghouralal S: Primary neoplasms of the central nervous system in Trinidad. Trop Geogr Med 1984;36:189-191.

31 Hospital Universitario Central de Asturias: Multiple cancer in the tumor register of the Central University Hospital of Asturias. Oviedo, 2005. www.hca.es/html/servicios/ rt/RT8/rt8.htm (accessed September 29, 2006).

32 Sadjadi A, Malekzadeh R, Derakhshan MH, Sepehr A, Nouraie M, Sotoudeh M, Yazdanbod A, Shokoohi B, Mashayekhi A, Arshi S, Majidpour A, Babaei M, et al: Cancer occurrence in Ardabil: results of a populationbased cancer registry from Iran. Int J Cancer 2003;107:113-118

33 Shuangshoti S, Tangghai P, Netsky MG: Neoplasms of the nervous system in Thailand. Cancer 1969;23:493-496.

34 Slovenia Cancer Registry, Cancer incidence in Slovenia 2003. Ljubljana, Onkološki inštitut, Register raka za Slovenijo, 2006.

- 35 Suh YL, Koo H, Kim TS, Chi JG, Park SH, Khang SK, Choe G, Lee MC, Hong EK, Sohn YK, Chae YS, Kim DS, et al: Tumors of the central nervous system in Korea: a multicenter study of 3,221 cases. J Neurooncol 2002;56:251-259.
36 Swedish Cancer Registry: Cancer Incidence in Sweden 2005. Stockholm, National Board of Health and Welfare, 2007.

37 Wen-Qing H, Shi-Ju Z, Qing-Sheng T, JianQing H, Yu-Xia L, Qing-Zhong X, Zi-Jun L, Wen-Cui Z: Statistical analysis of central nervous system tumors in China. J Neurosurg 1982;56:555-564.

38 Parkin DM, Pisani P, Ferlay J: Estimates of the worldwide incidence of twenty-five major cancers in 1990. Int J Cancer 1999;80: 827-841.

39 Deorah S, Lynch CF, Sibenaller ZA, Ryken TC: Trends in brain cancer incidence and survival in the United States: Surveillance, Epidemiology, and End Results Program, 1973 to 2001. Neurosurg Focus 2006;20:E1.

-40 Hoffman S, Propp JM, McCarthy BJ: Temporal trends in incidence of primary brain tumors in the United States, 1985-1999. Neuro Oncol 2006;8:27-37.

41 Kaneko S, Nomura K, Yoshimura T, Yamaguchi N: Trend of brain tumor incidence by histological subtypes in Japan: estimation from the Brain Tumor Registry of Japan, 1973-1993. J Neurooncol 2002;60:61-69.

42 Lönn S, Klaeboe L, Hall P, Mathiesen T, Auvinen A, Christensen HC, Johansen C, Salminen T, Tynes T, Feychting M: Incidence trends of adult primary intracerebral tumors in four Nordic countries. Int J Cancer 2004; 108:450-455.

43 Polednak AP, Flannery JT: Brain, other central nervous system, and eye cancer. Cancer 1995;75(suppl):330-337.

44 Saika K, Hirabayashi Y: Comparison of time trends in brain central nervous system cancer incidence (1973-97) in East Asia, Europe and USA, from Cancer Incidence in Five Continents Vols IV-VIII. Jpn J Clin Oncol 2008;38:650-652.

-45 Christensen HC, Kosteljanetz M, Johansen C: Incidences of gliomas and meningiomas in Denmark, 1943-1997. Neurosurgery 2003; 52:1327-1333.

-46 McCarthy BJ, Surawicz T, Bruner JM, Kruchko C, Davis F: Consensus conference on brain tumor definition for registration. Neuro Oncol 2002;4:134-145.

47 Goshen Y, Stark B, Kornreich L, Michowiz S, Feinmesser M, Yaniv I: High incidence of meningioma in cranial irradiated survivors of childhood acute lymphoblastic leukemia. Pediatr Blood Cancer 2007;49:294-297.

-48 Ron E, Modan B, Boice JD Jr, Alfandary E, Stovall M, Chetrit A, Katz L: Tumors of the brain and nervous system after radiotherapy in childhood. N Engl J Med 1988;319:10331039.

49 Umansky F, Shoshan Y, Rosenthal G, Fraifeld S, Spektor S: Radiation-induced meningioma. Neurosurg Focus 2008;24:E7.

50 Sadetzki S, Modan B, Chetrit A, Freedman L: An iatrogenic epidemic of benign meningioma. Am J Epidemiol 2000;151:266-272. 
-51 Sadetzki S, Flint-Richter P, Ben-Tal T, Nass D: Radiation-induced meningioma: a descriptive study of 253 cases. J Neurosurg 2002;97:1078-1082.

52 Sadamori N, Shibata S, Mine M, Miyazaki H, Miyake H, Kurihara M, Tomonaga M, Sekine I, Okumura Y: Incidence of intracranial meningiomas in Nagasaki atomic-bomb survivors. Int J Cancer 1996;67:318-322.

- 53 Shintani T, Hayakawa N, Hoshi M, Sumida M, Kurisu K, Oki S, Kodama Y, Kajikawa H, Inai K, Kamada N: High incidence of meningioma among Hiroshima atomic bomb survivors. J Radiat Res (Tokyo) 1999;40:49-57.
54 Yonehara S, Brenner AV, Kishikawa M, Inskip PD, Preston DL, Ron E, Mabuchi K, Tokuoka S: Clinical and epidemiologic characteristics of first primary tumors of the central nervous system and related organs among atomic bomb survivors in Hiroshima and Nagasaki, 1958-1995. Cancer 2004;101: 1644-1654.

55 Malmer B, Adatto P, Armstrong G, Barnholtz-Sloan J, Bernstein JL, Claus E, Davis F, Houlston R, Il'yasova D, Jenkins R, Johansen C, Lai R, Lau C, McCarthy B, Nielsen H, Olson SH, Sadetzki S, Shete S, Wiklund F, Wrensch M, Yang P, Bondy M: GLIOGENE an International Consortium to Understand Familial Glioma. Cancer Epidemiol Biomarkers Prev 2007;16:1730-1734.
56 Wigertz A, Lönn S, Mathiesen T, Ahlbom A, Hall P, Feychting M; Swedish Interphone Study Group: Risk of brain tumors associated with exposure to exogenous female sex hormones. Am J Epidemiol 2006;164:629636.

57 Blitshteyn S, Crook JE, Jaeckle KA: Is there an association between meningioma and hormone replacement therapy? J Clin Oncol 2008;26:279-282. 